\title{
Foz do Iguaçu/PR na Perspectiva da Teoria do Espaço Turístico
}

Foz do Iguaçu/PR in the perspective of the Tourism Space Theory

ALEXANDRE GOSENHEIMER, Universidade Federal do Paraná, Brasil, (consultor26@gmail.com)

JOSÉ ELMAR FEGER, Universidade Federal do Paraná, Brasil, (elmar.josefeger@gmail.com)

SARAH MARRONI MINASI, Universidade Vale do Itajaí, Brasil (sarahminasi@gmail.com)

João Eugenio Marynowski, Universidade Federal do Paraná, Brasil, (jeugenio@ufpr.br)

THALYSON MISSAEL DA SILVA, Universidade Federal do Paraná, Brasil, (thalysonmike@yahoo.com.br)

\section{RESUMO}

O artigo tem como objetivo classificar e hierarquizar o município Foz do Iguaçu/PRcom base nos pressupostos de Boullón. Para isso considera o papel que desempenha e a hierarquia que assume perante os demais destinos turísticos brasileiros, baseando-se na origem de sua demanda. A pesquisa é classificada como exploratória e descritiva de abordagem qualitativa-quantitavia com um recorte longitudinal. A coleta dos dados está apoiada em fontes bibliográficas e documentais. Os dados foram obtidos em relatórios de pesquisa de demanda, artigos científicos e informações sistematizadas da plataforma TripAdvisor.A análise dos dados indica que o município de Foz do Iguaçu, no que diz respeito à função espacial, constitui-se um centro turístico de distribuição, em especial, para os centros turísticos de Ciudad del Este e Puerto Iguazu, Paraguai e Argentina respectivamente. Quanto à abrangência, tomando como base a demanda externa classifica-se como um destino internacional não limítrofe. 
No que diz respeito à demanda interna, ostenta a posição de destino nacional, ocupando a posição 7, nível 3 com uma média de 17.600 turistas em um único dia. A pesquisa limitou-se a analisar o destino turístico Foz do Iguaçu, o qual se insere em um contexto de complementariedade com Puerto Iguazú (Argentina) e Ciudad del Este (Paraguai). Com isso, surge a necessidade de pesquisas futuras com dados dos países vizinhos. Como implicações práticas da investigação, aponta-se a possibilidade para que o destino turístico Foz do Iguaçu se torne um centro de estada.

Palavras-chave:Turismo. Espaço Turístico. Hierarquia de Destino Turístico, Foz do Iguaçu/PR.

\section{ABSTRACT}

The paper aims to classify and rank the city of Foz do Iguaçu / PR based on the theory of Boullón. It considers the role it plays and the hierarchy it assumes concerning other Brazilian tourist destinations, based on the place of origin of its demand. The research is classified as exploratory and descriptive with a qualitative-quantitative approach with a longitudinal cut. Bibliographic and documentary sources support data collection. The data were obtained from demand research reports, scientific papers, and systematized information from the TripAdvisor platform. Data analysis indicates that Foz do Iguaçu, in terms of spatial function, constitutes a tourist distribution center, especially for Ciudad del Este and Puerto Iguazu, Paraguay, and Argentina, respectively. As for the scope, based on external demand, it is classified as a non-bordering international destination. About domestic demand, it boasts the position of a national destination, occupying position 7, level 3, with an average of 17,600 tourists in a single day. The research was limited to analyzing the tourist destination Foz do Iguaçu, inserted in a context of complementarity with Puerto Iguazú (Argentina) and Ciudad del Este (Paraguay). Thus, there is a need for future research with data from neighboring countries. As practical implications of the investigation, the possibility is pointed out that the tourist destination Foz do Iguaçu becomes a center of stay. 
Keywords:Tourism, Tourist Space, Tourist Destination Hierarchy, Tourist Space, Foz do Iguaçu / PR.

\section{INTRODUÇÃO}

Nos últimos anos, a preocupação com o território ficou em evidência, objetivando, principalmente, subsidiar as políticas de desenvolvimento tanto público como privadas. É no território que ocorre a maioria das relações, interconexões e interdependências sociais e funcionais do espaço (Cury, 2010). Nesse sentido, para entender a dinâmica socioeconômica e elaborar estratégias adequadas, deve-se verificar a distribuição das atividades e práticas no espaço (Lacoste, 1988; Feger, 2010).

Nesse sentido Boullón (2006) propôs que o turismo é uma atividade que tem direta relação com o entorno geográfico no qual se desenvolve. De modo geral, observa-se que as práticas do turismo são desenvolvidas em vários âmbitos geográficos que ultrapassam os limites políticos da unidade municipal.

No debate sobre a dimensão espaço e território no turismo, Pearce (2003) expõe que a maior parte dos modelos teóricos continuam sendo um sistema origem-ligação-destino. Esses três elementos recebem ênfase diferente em distintas teorias defendidas por vários autores mantendo a essência espacial. Nessa linha, o turismo consiste em um sistema no qual ocorre uma combinação entre vários conjuntos de empreendimentos, tais como: hotéis, restaurantes, atrativos, os quais se encontram espacialmente organizados com a finalidade de atender as necessidades dos turistas (Boullón, 2006). Com base nisso, o turismo abarca dimensões sociais, políticas, econômicas e culturais (Alvares et al., 2019).

A fim de contribuir com 0 debate e alargar as discussões sobre 0 espaço turístico, elegeu-se como unidade de análise o município de Foz do IguaçU/PR. É considerado o principal destino turístico do Paraná, sendo as Cataratas do Iguaçu, seu atrativo turístico mais conhecido (Castro, 2020). Além da sua relevância no contexto do turismo estadual e nacional, a 
escolha de Foz do Iguaçu foi baseada na disponibilidade de dados sobre o fluxo turístico.

Foz do Iguaçu está localizada na tríplice fronteira com Argentina e Paraguai. O município de Foz do Iguaçu possui uma população estimada em 258.480 habitantes (IBGE, 2019). A região agrega uma população de aproximadamente 900 mil habitantes (IBGE, 2019). A proximidade com os outros países potencializa alguns aspectos como acesso a aeroportos internacionais, mobilidade entre países (Silva \& Gândara, 2016).

O destino turístico apresenta como princiapis atrativos além das Cataratas do Iguaçu, a Hidrelétrica de Itaipu, Parque das Aves, Parque Nacional do Iguaçu e o Marco das Três Fronteiras, que se situa no lado argentino à margem do rio Iguaçu e no lado paraguaio fica à margem direita do rio Paraná, constituindo o ponto em que as fronteiras da Argentina, Brasil e Paraguai se encontram (Castro \& Gândara, 2018). O município também contempla uma série de outros atrativos turísticos em função das etnias que integram o processo de formação de Foz do Iguaçu, como a Mesquita "Omar Ibn Al Khattab" e o Templo Budista. (SMT, 2019a), entre outros.

Pesquisas anteriores abordaram as contribuições da aplicação da teoria do espaço turístico para o corredor turístico da região centro-norte do Estado do Piauí (Ramos \& Lopes, 2012; 2013). Feger et al., (2013) aplicaram a teoria ao estudar o turismo em fronteiraentre os estados de Santa Catarina e Rio Grande do Sul. Suzart et al.,(2016) buscaram aliar a teoria do espaço turístico com as novas tecnologias, em especial, o georreferenciamento para análise do distrito de Paranapiacaba/SP. Costa e Lucca Filho (2016) apresentam uma reflexão teórica sobre turismo e espaço urbano apoiados em Boullón.

A teoria do espaço turístico de Boullón (2006) está discutida na literatura e ainda é utilizada atualmente, desmonstrando ser uma abordagem teórica válida para compreensão da organização do turismo no espaço (Fratucci, 2014). Dada a capacidade da teoria proporcionar uma 
base para análise de dados, facilita a elaboração de indicadores comparáveis. A fim de melhorar a tomada de decisões no setor público ou privado, a utilização de indicadores se mostra eficaz nos destinos turísticos (Miskalo-Cruz \& Gândara, 2016). O monitoramento por meio de indicadorespossibilita verificar se a informação coletada é relevante para compreender a situação atual, bem como, observar se ocorreram mudanças tanto de comportamento como de posicionamento frente a situações específicas de forma constante e consistente.

A partir do contexto apresentado a pesquisa orienta-se pelo seguinte questionamento: Como se aplicam os pressupostos de Boullón para a classificação hierárquica e função espacial do destino turístico Foz do Iguaçu de acordo com sua demanda? Para isso tem como objetivo classificar e hierarquizar o município Foz do Iguaçu/PR com base em Boullón.

De acordo com o objetivo proposto essa pesquisa se caracteriza como exploratória e descritiva com abordagem quali-quantitativa apoiada na pesquisa bibliográfica e documental. Os dados foram coletados em publicações científcias, relatórios técnicos e na plataforma TripAdvisor,os quais foram analisados a partir da teoria do espaço turístico de Boullón.

A estrutura do artigo, contempla além desta introdução, umsegundo tópico em que são trabalhados os conceitos de espacialização e hierarquia, classificações por volume da demanda, bem como a função que o destino empreende. Na sequência, trata-se da metodologia adotada para coleta e análise dos dados. Posteriormente são apresentados os resutlados e principais discussões. Por fim, estão descritas as considerações finais, implicações práticas, limites e sugestões para pesquisas futuras.

\section{REFERENCIAL TEÓRICO}

O conceito de espaço "está associado a uma porção específica da terra identificada seja pela natureza, seja por um modo particular como o homem que ali imprimiu as suas marcas, seja como simples localização" (Corrêa, 2000, p. 15). Portanto, a palavra espaço temseu uso associado a 
diferentes escalas, global, continental, regional, da cidade, do bairro, da rua, da casa e um cômodo no seu interior.

Acerca da superfície turística seus elementos básicos são descritos "como todo espaço geográfico, que não pode ser definido por fronteiras euclidianas, mesmo porque pelo menos um dos seus elementos básicos the é exterior - a demanda" (Rodrigues, 2011, p. 74). Os elementos do espaço turístico, além da demanda, são: oferta turística, serviços, transportes, infraestrutura, poder de decisão e de informação, sistema de promoção e de comercialização (Rodrigues, 2011; Costa e Lucca Filho, 2016).

A relação entre todos estes elementos se dá com o processo de produção-consumo turístico, que gera uma nova realidade socioespacial diferenciada denominada destino, e que participa ao mesmo tempo de aspectos setoriais e geográficos (Barrado-Timón, 2004).Dessa forma, o destino é um subsistema formado por elementos espaciais, administrativos e produtivos, assim como, pelo conjunto de suas inter-relações e os efeitos que produzem, que são fundamentalmente setoriais e geográficos (BarradoTimón, 2004; Castro \& Gândara, 2018).

Assim, destino turístico apresenta como característica a centralidade de serviços e atrativos estruturados e adaptados às necessidades dos turistas (Valls et al., 2006; Costa e Lucca Filho, 2016). Cabe destacar que apesar da relevância na motivação dos turistas, os atrativos precisam ser considerados em suas relações com o sistema turístico (Pimentel, 2020). Além disso, para a atividade turística é preciso considerar a relação entre a oferta e a demanda, bem como a intervenção da superestrutura (Alvares et al., 2019).

\section{Classificação por volume da demanda}

A demanda turística expressa o êxito de um centro turístico e a falta dela, naturalmente, o seu fracasso (Boullón, 2005). A partir da teoria de Boullón (2005) constata-se que de nada adianta classificar o atrativo no mais alto nível se este não motiva a demanda para o qual foi proposto. Logo, 
trata-se do entendimento que a quantidade precisa ser expressa em qualidade. Assim, para esse entendimentoé necessário conhecer do destino as variáveissobre o perfil da demanda (Boullón, 2005; Castro \& Gândara, 2018; Pimentel, 2020) (Tabela 1).

Tabela 1

Classificação por demanda

\begin{tabular}{c|l}
\hline \multicolumn{1}{l|}{ Posição } & Descrição \\
\hline $\mathbf{1}$ & Número de visitantes \\
\hline $\mathbf{2}$ & Estada dos visitantes \\
\hline 3 & Sazonalidade de demanda e duração de temporada \\
\hline $\mathbf{4}$ & Número de habitações de uso turístico \\
\hline $\mathbf{5}$ & Despesa diária dos visitantes \\
\hline
\end{tabular}

Nota. Fonte: Adaptado de "Os municípios Turísticos" de R. C. Boullón, 2005, p.

Da combinação das posições 01 a 03 (Tabela 1), resulta a quantidade de visitantes simultâneos, sendo este o primeiro indicador para avaliar a importância de um centro turístico. O quantitativo de visitantes simultâneos é categorizado conforme o ranking, apresentado na Tabela 2. É importante medir e quantificar os visitantes simultâneospara, por exemplo, calcular a capacidade de carga dos equipamentos. Além disso, conhecer o perfil do turista pode auxiliar na avaliação da necessidade de ampliar unidades habitacionais, por exemplo.

Tabela 2

Classificação dos municípios turísticos com base na demanda simultânea

\begin{tabular}{c|c|c}
\hline Posição & Visitantes simultâneos & Nível \\
\hline
\end{tabular}




\begin{tabular}{|c|c|c|}
\hline 1 & -200 & 1 \\
\hline 2 & 200 a 1.000 & \\
\hline 3 & 1.001 a 2.000 & 2 \\
\hline 4 & 2.001 a 3.000 & \\
\hline 5 & 3.001 a 6.000 & \\
\hline 6 & 6.001 a 10.000 & 3 \\
\hline 7 & 10.001 a 20.000 & \\
\hline 8 & 20.001 a 30.000 & \\
\hline 9 & 30.001 a 40.000 & \\
\hline 10 & 40.001 a 60.000 & 4 \\
\hline 11 & 60.001 a 80.000 & \\
\hline 12 & 80.001 a 100.000 & \\
\hline 13 & 100.001 a 120.000 & 5 \\
\hline 14 & 120.001 a 150.000 & \\
\hline 15 & +150.000 & \\
\hline
\end{tabular}

Nota. Fonte: Adaptado de "Os municípios Turísticos" de R. C. Boullón, 2005, p.

Cabe diferenciar que os fluxos de visitantes podem ser divididos em turista e excursionista. Por vezes os termos são tratados como sinônimos, mas do ponto de vista técnico, tem suas diferenças. Uma delas, a qual interessa para este estudo, é que o primeiro passa um período superior a 24 horas no núcleo receptivo, ou seja, com pernoite, enquanto o segundo visita por um período mais curto o suficiente para não envolver pernoite (Middleton \& Clarke, 2002). Para efeitos da metodologia apresentada por Boullón (2005), 
pode-se trabalhar com a combinação dos dois perfis, ou somente com o perfil do turista, como a opção escolhida nesta pesquisa (mais usual).

\section{Classificação por função}

A discussão que acompanha a teoria do espaço turístico de Boullón apresenta possibilidades de categorizar os espaços turísticos. Nessa seção serão apresentadas as categorias: centro turístico; centro de distribuição; centro de estada; centro de excursão; centro de escala.

Centro turístico refere-se a todo conglomerado urbano que, em seu próprio território ou área de influência, possui um ou mais atrativos turísticos de tipo e hierarquia suficientes para motivar uma viagem. De acordo com a função que desempenham podem ser de quatro tipos, centros de distribuição, centros de estada, centros de excursão e centros de escala (Boullón 2006). Os centros de distribuição são aqueles quese caracterizam pela permanência do turista de um a três pernoites, porque basicamente sua finalidade é que o turista percorra o maior número de atrativos na mesma localidade (Boullón, 2006). Os centros de estada são dependentes de um único tipo de atrativo principal. Este é o caso, por exemplo, de centros turísticos de praia, esqui, águas termais ou jogos de azar. Nesse caso, o atrativo se caracteriza como do tipo que leva o visitante a querer praticar a mesma atividade todos os dias durante a sua estada no local frequentado, estimulando estadas mínimas a partir de cinco pernoites (Boullón, 2006).

Os centros de excursão não são estritamente turísticos, pois sua demanda origina-se dos habitantes de áreas urbanas próximas, que se dirigem ao centro durante os fins de semana e em período de férias, e permanecem ali menos de 24 horas. Vale ressaltar, que mesmo em se tratando de turistas, muitas vezes realizam a sua hospedagem em um centro de distribuição próximo. Nessa situação, podem comportar-se como excursionistas. Por fim, os centros de escala apesar de não serem tão comuns como os anteriores, se configuram no espaço entre origem e destino, em 
função da distância. Muitas vezes, corresponde a um local onde se troca o modal de transporte de aéreo para terrestre ou vice-versa (Boullón, 2006).

Essas são classificações gerais, contudo Boullón (2006) apresenta uma classificação não tão comum, mas que, em virtude do objeto deestudo vale descrever. O complexo turístico são grandes agrupamentos de atrativos que estimulam permanência igual ou superior a 3 dias. Nesses casos, principalmente o atrativo âncora não deve ser do mesmo tipo que compõe o centro turístico de estada e sim característico de centro de distribuição (lagos, montanhas, lugares históricos, ruínas, sítios arqueológicos etc.).

Mediante estas categorias, é possível entender se um destino consegue atrair e reter os turistas. Além disso, permitem elencar indicadores que demonstrem as funções exercidas pelos espaços turísticos, suplementando informações úteis para o planejamento e desenvolvimento do turismo.

\section{Classificação a partir da origem da demanda}

Uma característica essencial aos destinos turísticos é ter atrativo turístico, matéria-prima do turismo (Boullón, 2006). Entretanto, torna-se relevante obter indicadores que respondam questionamentos como: O que atrai o turista a determinado lugar? Qual a distância que o turista está disposto a percorrer até o seu destino? Questões como essas estão diretamente relacionadas a hierarquia do destino turístico (Boullón, 2005). Nesse sentido, um destino pode assumir classificações quanto à origem dos turistas e visitantes nacionais ou internacionais. A hierarquização possibilita entender a capacidade de atração e gerar indicadores da capacidade de atração que um destino (Boullón, 2005) (Tabela 3). 
Tabela 3

Hierarquia do destino turístico de acordo com origem da demanda

\begin{tabular}{|c|c|c|c|}
\hline Origem & \multicolumn{2}{|c|}{ Capacidade de atração } & Distância \\
\hline \multirow{3}{*}{ 1. Nacional } & \multirow{3}{*}{1.1 Interno } & 1.1.1 Local & até $200 \mathrm{~km}$ \\
\hline & & 1.1.2 Regional & até 500km \\
\hline & & 1.1.3 Nacional & superior a $500 \mathrm{~km}$ \\
\hline \multirow{3}{*}{ 2.Internacional } & \multirow{3}{*}{ 2.1 Receptivo } & 2.1.1 Fronteiriço & entre 50 e $200 \mathrm{~km}$ \\
\hline & & 2.1.2 Limítrofe & $\begin{array}{l}\text { não considera } \\
\text { distância, } \\
\text { apenas se faz } \\
\text { fronteira }\end{array}$ \\
\hline & & $\begin{array}{c}2.1 .3 \text { Não- } \\
\text { limítrofe }\end{array}$ & $\begin{array}{c}\text { não considera } \\
\text { distância e que } \\
\text { não faça } \\
\text { fronteira }\end{array}$ \\
\hline
\end{tabular}

Nota. Fonte: Adaptado de "Os municípios Turísticos" de R. C. Boullón, 2005, p.

Sobre o turismo internacional são atribuídas as seguintes classes: fronteiriço, aquele que faz fronteira com o município destino; limítrofe, quando faz fronteira com o país onde está inserido o destino; não limítrofe, aquele não faz fronteira com o país a ser visitado (Boullón, 2005).

Quanto ao turismo interno, sabe-se que de acordo com os modelos gravitacionais (Rabahy, 2003), a tendência é que os destinos atraiam maior fluxo de pessoas de localidades próximas, porém, na medida em que o atrativo assume maior importância passa a atrair fluxos de maior distância. Neste caso, assume-se para este artigo que um destino passa a ser nacional ao atrair um fluxo mais significativo de turistas originários de localidades acima de 500 km. Deve-se atentar que um não exclui o outro, mas se 
considera que na medida que a atratividade do destino evolui, passa a atrair pessoas da região, do país, e mesmo internacionais.

A teoria de Boullón mostra uma visão sistêmica sobre a interação do turismo no espaço geográfico e traz para o centro da análise a inter-relaçao de seus principais componentes (Alvares et al., 2019). Ao mesmo tempo a proposta de Boullón mostra que a regionalização é uma forma de agregar recursos, atrativos e equipamentos turísticos para maximizar benefícios da atividade turística (Ramos \& Lopes, 2013; Castro \&Gândara, 2018).

Uma possibilidade pode ser combinar o modelo de Boullón com outro que se assemelha a ele no que diz respeito a função espacial, mas difere quanto a origem dos dados e variáveis consideradas. Tal configuração é proposta por Liu et al., (2012) para compreender a relação entre destinos turísticos. O método toma como parâmetro o fluxo de deslocamento dos turistas no espaço a fim de categorizar o destino quanto a sua relevância regional. Para classificar os espaços, diferente de Boullón, Liu et al., (2012) organizam os dados a partir da teoria das redes (Granovetter, 1973; Scott, 2000; Scott et al., 2008; Walter et al., 2010; Wu, 2012). Uma variável considerada envolve a centralidade do destino e evidencia a sua importância quanto a capacidade de recepção de turistas, atuando como portal de entrada para a região. Outra variável corresponde ao grau de proximidade entre os destinos de forma a identificar a sua condição de aproximação com os demais destinos regionais. Uma terceira categoria envolve o grau de intermediação dos destinos regionais, permitindo discutir a condição de controle e dependência entre os diversos destinos localizados em determinado espaço (Liu et al., 2012). A partir da combinação da centralidade, proximidade e intermediação os destinos podem ser classificados em Centros de Distribuição de Fluxos, Centro de Fluxos Turísticos, Destinos de Passagem, Destinos de Passeio, Destinos Anexados, Destinos Isolados (Liu et al., 2012). Essa abordagem pode ser interessante, no entanto a sua consideração no presente estudo se mostrou inviável, visto que essa 
perspectiva demandaria colher informações de um conjunto de destinos, o que não faz parte do seu escopo, mas pode ser objeto de futuras análises.

\section{METODOLOGIA}

Em função do objetivo principala pesquisa desenvolvida é classificada como exploratória e descritiva, por proporcionar maior familiaridade com o desenvolvimento do turismo em Foz do Iguaçu e visa estudar as características da oferta turística e da demanda nesta região. A pesquisa é de abordagem qualitativa-quantitativa pela busca do entendimento das relações entre os três campos temáticos considerados, ou seja, espaço turístico, destino turístico e hierarquização. Ao mesmo tempo focou na classificação da oferta na perspectiva da espacialização do turismo a partir da origem da demanda baseado nos dados quantitativos coletados.

A coleta e análise de dados envolveu a triangulação de fontes documentais, especialmente banco de dados dos órgãos governamentais e trade turístico local combinadas com conteúdos teóricos provenientes de artigos produzidos sobre o tema. Além destas fontes, foi realizada a coleta automatizada de dados (Munzert et al., 2014) da plataforma TripAdvisor técnica conhecida no campo da informática por web scraping, em que foram tratados 65.000 comentários, dos quais se verificou o local de residência do emissor do comentário. O processamento dos dados foi realizado por meio do software estatístico $R$ que possui pacotes com funções especializadas para mineração de textos (Silge\& Robinson, 2017) que possibilitou lidar mais facilmente com o grande volume de dados. 0 procedimento para a coleta e operacionalização dos dados consistiu nos seguintes passos: i) aquisição dos dados dos comentários no site TripAdvisor; ii) pré-processamento e tabulação das origens das pessoas que comentaram a viagem ao destino analisado; iii) elaboração de tabela com todos os locais de origem nacionais e internacionais; iv) Geração de mapas com dados dos turistas quanto: origem/distância. 
A fim de facilitar a visualização das informações sobre origem da demanda, aplicou-se técnicas de georreferenciamento dos dados. Os dados coletados do site TripAdvisor e organizados em planilha do software Microsoft Excel foram inseridos no ambiente Quantum GIS - QGIS, na forma de um Sistema de Informações Geográficas - SIG. Os dados sobre a origem da demanda de turistas para o destino turístico Foz do Iguaçu (PR) foram agrupados por Regiões Geográficas Imediatas - RGl, uma nova divisão regional do Brasil apresentada pelo IBGE (2017). Os arquivos vetoriais (shapefile) com os dados espaciais das RGI são disponibilizados pelo IBGE.

O processamento dos dados classificou a camada das RGI de acordo com o gradiente dos valores de volume de turistas e distância. O plugin Oursins foi utilizado para gerar os resultados relacionados a distância da origem até o destino turístico Foz do Iguaçu. Com a ferramenta de classificação da tabela de atributos os dados foram processados para representar o volume de turistas.

Para demonstrar o volume do fluxo de turistas de acordo com a RGI de origem foi utilizada a representação por círculo proporcional. Nessa opção o atributo volume (em porcentagem) foi representado pelo diâmetro, no qual quanto maior o diâmetro, maior a porcentagem de turistas com a mesma origem, o inverso é também verdadeiro. O mesmo procedimento foi utilizado para representar os fluxos internacionais. Para isso o volume foi representado por círculo proporcional de acordo com o país de origem dos comentários.

Após a sistematização dos dados, as análises buscaram traçar um paralelo entre as fontes consultadas, os comentários do TripAdvisor, publicações científicas sobre o destino turístico e as pesquisas e controles de fluxos apurados pela gestão do turismo no destino (Parque das Cataratas e Secretaria de Turismo).

\section{RESULTADOS E DISCUSSÃO}


Até aqui foram tratados os aspectos teóricos do espaço turístico ancorado em Boullón (2005; 2006). A partir desta discussão, passa-se a tratar da apresentação dos dados conforme proposto no objetivo deste estudo, ou seja, a aplicação dos conceitos no destino turístico de Foz do Iguaçu. Dessa forma, os dados são discutidos na sequência, classificando o destino a partir da sua função espacial, em seguida a categorização a partir da demanda simultânea e finalizando com a classificação a partir da origem dos turistas.

\section{A função espacial do destino}

Esta classificação do destino envolve a verificação dos fluxos que ocorrem no espaço em que se situa o destino. A discussão que se pretende neste tópico, é entender qual o papel desempenhado pelo destino em função da circulação dos turistas internamente ao território do destino.

Tal debate já foi feito por Boullón (2006), ao discorrer sobre o conceito de complexo turístico e alegar que há necessidade de no mínimo um centro de distribuiçãovisto que no complexo internacional de Cataratas de Iguaçu, possui até três centros turísticos próximos. A cidade de Foz do Iguaçu pode ser classificada como um centro de estada e de distribuição, visto que diferente dos anos 1990, período em que os turistas visitavam unicamente as Cataratas e o Marco das Três Fronteiras. Hoje incluem a oferta turística do entorno, passando para os municípios que margeiam o lago de Itaipu (Massukado \& Teixeira, 2006; Ramos \& Lopes, 2012; 2013).

Nesse sentido, a classificação do destino depende não só da circulação de pessoas, mas do tipo de atrativo que possui. Portanto, discorda-se neste artigo de Ramos e Lopes (2012), ao alegarem que Foz do Iguaçu se caracteriza como um Centro Turístico de Estada. De acordo com as características da oferta e a classificação por função, Foz do Iguaçu carece de atrativo que motive o turista permanecer para realizar a mesma atividade por vários dias. De acordo com Boullón (2005), para se classificar 
nesta categoria o centro teria que gerar no mínimo5 pernoites, além de contar com um tipo de atrativo específico. Foz do Iguaçu, de acordo com dados da Secretaria Municipal de Turismo (2019b), nos últimos 19 anos mantém o tempo médio de permanência em 3 dias, além de ter os tipos de atrativos que não proporcionam interesse do turista realizar a mesma atividade todos os dias.

Dessa forma, entende-se que Foz do Iguaçu se caracteriza como um Centro Turístico de Distribuiçãovisto que por suas características assume o papel de distribuir demanda aos municípios da região. Adicionalmente, reforçando essa perspectiva, considera-se a divulgação do trade turístico na qual se verifica que a cidade estimula de forma mais clara e natural 0 turismo nos países vizinhos, Paraguai e Argentina. O tempo atual de permanência demonstra justamente essa condição, distribuição de demanda ao longo de uma quantidade expressiva de atrativos (ver Visit Iguaçu, 2020), mas não havendo um único atrativo capaz de fazer o turista voltar a ele vários dias seguidos.

Para além de analisar somente o objeto de estudo Foz do Iguaçu, considera-se a sua articulação e complementariedade com os municípios vizinhos (Silva \& Gândara, 2016), e assim, pode-se classificar esse conjunto como um Complexo turístico. Esta categoria "chega a ser uma derivação dos centros turísticos de distribuição que alcançam uma ordem superior" (Boullón, 2006, p.77). O encontro dos três centros turísticos (Foz do Iguaçu, Ciudad del Este e Puerto Iguazu) explica essa definição e corrobora com o tempo de permanência do turista neste destino.

Dessa forma, consequentemente não se enquadra como centro turístico de diversão ou de escala, em função de que neste caso as funções espaciais não podem ser cumulativas ao que se tem de principal classificação que é de centro de distribuição. Todavia, vale alertar para o fato de que é possível que um determinado espaço possa desempenhar funções diferentes dependendo dos agentes envolvidos, seguindo os 
preceitos da espacialidade diferencial de Lacoste (1988). Essa discussão, porém, não faz parte do escopo desta pesquisa.

\section{Demanda simultânea do destino}

A demanda simultânea consiste em determinar o volume de turistas que frequentam simultaneamente um determinado destino. Uma informação que permite conhecer o número de visitantes, a sazonalidade e a taxa de permanência. Para o caso de Foz do Iguaçu, a partir dos dados da Secretaria de Turismo do município, temos:

- Média mensal de visitantes: 170.957

- Dias de permanência: 3,1

Para verificar o número médio de turistas simultâneos adaptou-se a fórmula usada na hotelaria (Petrocchi apud Feger et al., 2013)

$$
V S=\left(N V^{*} T P\right) / N D \text {. }
$$

Onde, VS = visitantes simultâneos / NV = número de visitantes / TP = dias de permanência / ND = dias disponíveis no período (mês comercial)

Logo temos que,

$$
\begin{gathered}
V S=\left(170.957^{*} 3,1\right) / 30 . \\
V S=17.666
\end{gathered}
$$

Com o resultado é possível classificar (ver Tabela 2), o município no ranking proposto por Boullón (2005), isto é, Foz do Iguaçu ocupa o nível 3 e posição 7 (10.001 a 20.000). Em relação a sazonalidade optou-se por extrair a média simples mensal a partir do valor total anual. O cálculo demonstra que em Foz do Iguaçu ocorre uma média de 17.666 turistas no município em um mesmo dia.

Esse procedimento de classificação pode ser útil no sentido de comparar qualquer município do qual se tenham as variáveis indicadas. Uma possibilidade, na medida em que se tenha dados confiáveis das diversas regiões turísticas, seria construir uma série histórica deste indicador, 
auxiliando nas definições de estratégias e mesmo, monitorando os resultados das ações implementadas nestes espaços.

\section{Origem da demanda do destino}

Quanto a origem da demanda o destino pode se enquadrar como nacional e internacional. Inicia-se a análise utilizando-se os dados levantados a partir do TripAdvisor. A partir da aglutinação dos municípios de origem dos turistas em função das RGI para os dados nacionais e por países para os dados internacionais. Os dados foram analisados em círculos concêntricos e gradiente de cor, essa forma de apresentação dos dados se fez necessária dada a grande quantidade de municípios encontrados em mais de sessenta mil comentários.

Em primeira análise, observa-se as cores que tendem ao mais escuro identificam que os comentaristas eram originários de regiões mais distantes, em uma faixa de $356 \mathrm{~km}$ até $1019 \mathrm{~km}$ para o âmbito nacional (Figura 1). Dessa forma, pode-se inferir que o turismo interno do município consegue atrair visitantes posicionando-se entre regional e nacional.
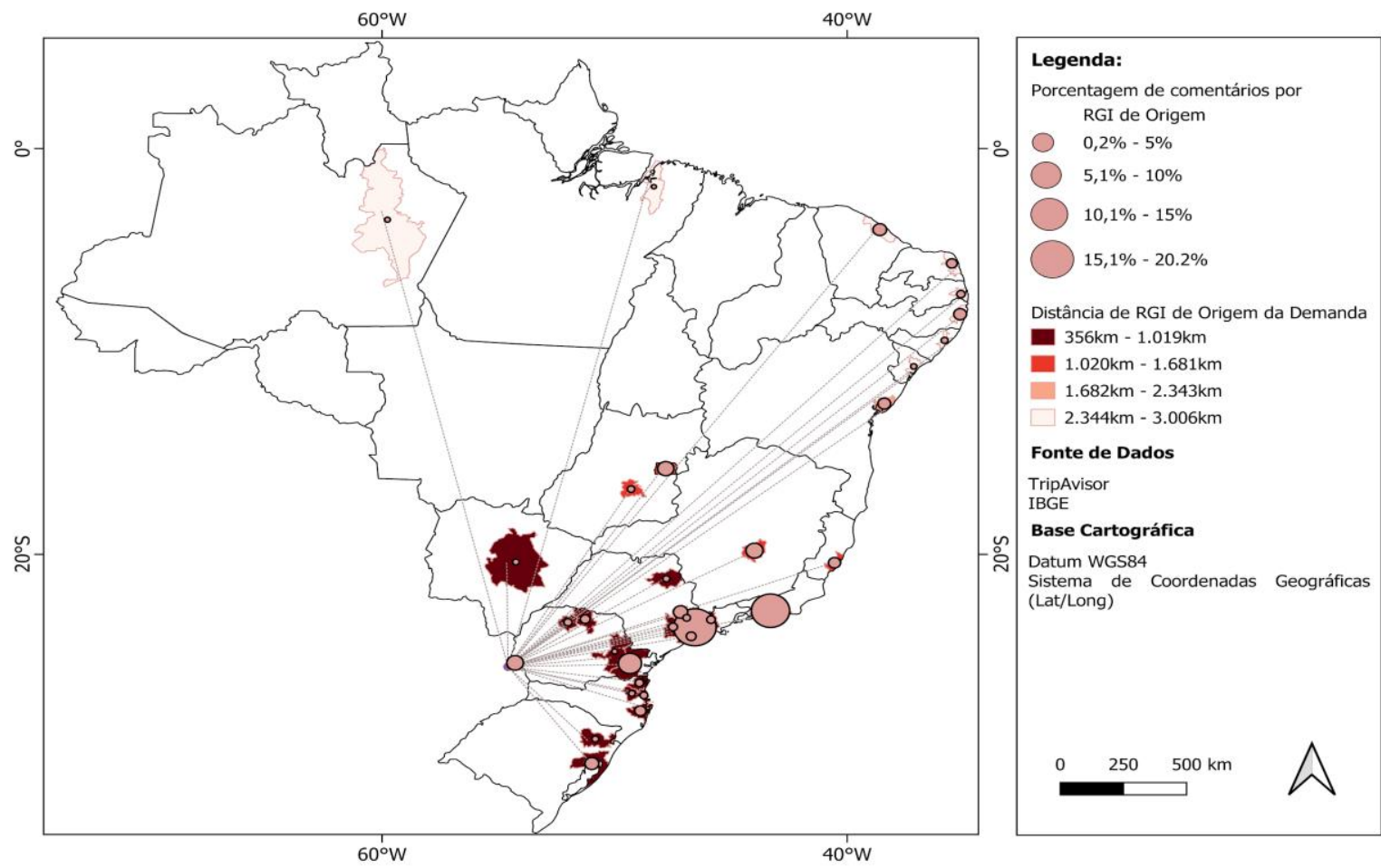
Figura 1.Classificação pela origem da demanda nacional

Além disso, pode-se verificar que existem certas concentrações de turistas em determinadas áreas do país, ao se olhar para os círculos formados pelo percentual de turistas. Nesse caso, um grande círculo situado na RGI da capital de São Paulo, indicando que aproximadamente $15 \%$ a $20 \%$ dos turistas originam-se desta área. Em seguida, verifica-se que em torno de 10\% a 15\% dos comentários foram emitidos por residentes da RGI que agrega a capital Rio de Janeiro. Um terceiro círculo que se destaca está na RGI que integra Curitiba, correspondendo de 5\% a 10\% de comentários. Destaca-se que somente estas regiões concentram próximo de um terço dos turistas que visitam Foz do Iguaçu. Ainda, verifica-se que em torno de $76 \%$ dos turistas nacionais se originam de regiões com distância acima de $500 \mathrm{~km}$ do destino estudado. A partir dos dados, identifica-se que o destino consegue atrair uma demanda nacional, concentrada nas regiõesSudeste e Sul. Porém, Foz do Iguaçu recebe turistas de praticamente todos os estados brasileiros, conforme pode ser verificado pela distribuição de círculos.

Com base nos dados do Inventário Técnico de Estatísticas Turísticas de Foz do Iguaçu ano-base 2012 (SMT, 2019b), verifica-se que em torno de 82\% dos turistas nacionais são originários dos Estados do Paraná, Rio de Janeiro, São Paulo, Santa Catarina e Rio Grande do Sul. Esse fato corrobora os dados obtidos do TripAdvisor. A soma dos percentuais de comentários das regiões de Santa Catarina (Blumenau, Joinville, Itajaí, Florianópolis) e Rio Grande do Sul (Porto Alegre) chega-se a 6\%, o que valida os dados do TripAdvisor com os dados colhidos pela Secretaria de Turismo.

Nos dados do site TripAdvisor, verificou-se que no âmbito da procedência internacional de comentários de viagem à Foz do Iguaçu, abrange 83 países. Observa-se no mapa que apesar da diversidade de países, a América Latina concentra a maior parte dos turistas, e grande parte deles não são limítrofes (Figura 2). Pelo volume de turistas, observa-se 
nos círculos que se destacamos Estados Unidos com proporção entre 15\% e $20 \%$, seguido do Reino Unido entre $10 \%$ e $15 \%$.

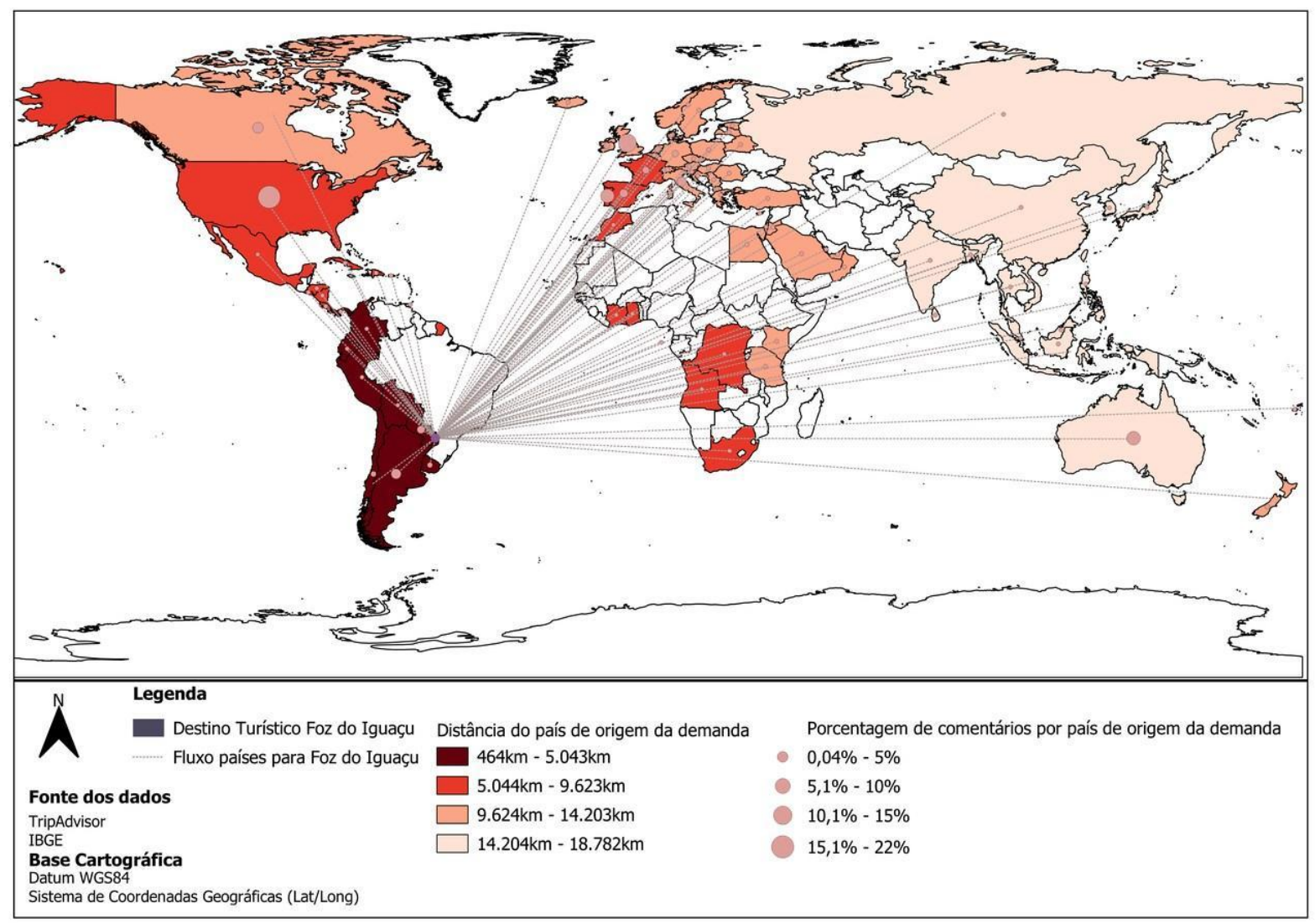

Figura 2. Classificação pela origem da demanda internacional

Dessa forma, pode-se classificar Foz do Iguaçu como destino internacional não-limítrofe visto que apresenta fluxo turístico nos três níveis, mas se destaca pelos $90 \%$ dos turistas internacionais originários de localidades que não fazem limites com o estado em que se localiza o destino analisado.

Nota-se que igual constatação, foi obtida no estudo de demanda turística dos anos 2011 e 2012, em que "destacam-se como grandes emissores, em nível internacional, o Reino Unido e os Estados Unidos (EUA), superando muitos países da América Latina" SMT/SETU (2012, p. 10). Apesar da localização privilegiada junto ao MERCOSUL, os maiores emissores internacionaisnão eram dos países limítrofes como os do citado mercado (Vieira et al.,2014). 
Além do recorte das pesquisas citadas, existem estatísticas acumuladas pelo Instituto Chico Mendes (ICMBio), órgão público federal, que administra o Parque Nacional do Iguaçu, onde se localiza o principal atrativo do município, as Cataratas do Iguaçu. Os relatórios informam que no ano de 2011, por exemplo, passaram por ali 1.394.187 turistas tendo como principal procedência estrangeira a Argentina com 257.709, e os EUA e Reino Unido contribuem com 26.946 e 19.730 visitantes respectivamente. Na época, o Instituto também registrou que Foz do Iguaçu através dos controles do Parque registrou presença de 160 nacionalidades.

Em dados atuais, segundo a estatal Agência de Notícias do Paraná (2020), em 2019 passaram pelo centro de visitantes do Parque Nacional do Iguaçu o total de 2.020.358 turistas, sendo a nacionalidade Argentina com maior participação entre os internacionais, 436.369. Para efeitos de comparação, EUA e Reino Unido, participaram com 49.109 e 24.002 visitantes, respectivamente. Assim, tais dados estão em conformidade com aquela contagem de 2011 sendo que estas nacionalidades estão entre as que mais se destacam em relação à totalidade. Ressalta-se também, que em 2019, foi registrada a passagem de 177 nacionalidades pelo Parque.

No que diz respeito à dispersão dos visitantes internacionais de Foz do Iguaçu, os dados do TripAdvisor são compatíveis com os dados apresentados pelo ICMBio (2012). O Parque das Cataratas do Iguaçu, o principal atrativo, pode ser considerado um termômetroa para medir o fluxo turístico do destino.

Entender o fluxo turístico que se desenvolve na região pode ser um instrumento de fomento para novos atrativos turísticos. Ao adotar a visão de complexo pode ampliar a oferta de opções aos turistas dos três centros envolvidos, a região ampliaria seu potencial de atração.

Uma primeira proposição, baseia-se na própria estrutura do sistema de ligação entre a origem dos turistas e os destinos no Brasil e na América Latina se constituírem em acessos rodoviários. Dessa forma faz sentido classificar os destinos turísticos a partir das distâncias como proposto por Boullón. Há 
críticas ao uso da teoria, a exemplo das proferidas por Almeida (2006) o qual propôs uma matriz de classificação de potencial turístico ao analisar os municípios de Guaratinguetá e Cunha (SP), alegando que a teoria proposta por Boullón seria simplista pela ausência de indicadores. Esse pensamento é contraposto por Soares e Cardozo (2012) ao alegarem que Almeida (2006) não aborda a questão da hierarquização dos destinos analisados. As contradições entre pesquisas salientam a necessidade de ampliar estudos.

Algumas constatações podem ser feitas em relação à teoria, uma delas diz respeito à questão sugerida por Boullon (2006) quanto à região de Foz do Iguaçu se constituir como um complexo turístico internacional. Esse fato se mantém e evolui atualmente, na medida em que, os atores locais, dos três países, se organizam para desenvolver o turismo de forma cooperada.

Uma segunda proposição, é que os indicadores obtidos fornecem condições de comparar destinos turísticos segundo as características de suas demandas. Nesse caso, há uma dificuldade no Brasil, visto que existem poucas pesquisas que segregam a demanda em nível municipal. Nesse caso, ao utilizar os dados da plataforma TripAdvisor, abre-se a possibilidade de realizar um estudo comparativo entre os destinos turísticos brasileiros, de um lado apontando a abrangência do mercado, e de outro, indicando possíveis expansões.

A aplicação da teoria aqui utilizada em estudos no Brasil, bem como, a sua disseminação na literatura nacional, revela que se trata de corpo teórico consistente para análises espaciais. O estudo aqui realizado também sugere constatações válidas, visto que a análise dos resultados demonstra que são perfeitamente compatíveis com as classificações propostas por Boullón. As críticas que se fazem ao modelo e os resultados de estudos subsequentes inspirados na teoria de Boullón trouxeram contribuições, mas ainda não oferecerem uma nova teoria. Assim, aponta-se para a sua validade e com isso incentiva a novas pesquisas utilizando outros destinos como objetos, a fim de se obter mais dados para a sua consolidação. 
Sugere-se ainda que se ampliem os estudos de casos para que se possa aprofundar a aplicabilidade da teoria do espaço turístico de Boullón.

\section{CONSIDERAÇÕES FINAIS}

A teoria do espaço turístico de Boullón é um clássico dos estudos do turismo. Nesse sentido, a proposta deste estudo se caracteriza como um exercício de revisita à teoria, possibilitando ampliar as discussões sobre a sua pertinência para a realidade atual. Portanto, é preciso considerar que a presente investigação não é conclusiva e sim exploratória, ainda que permita a formulação de proposições que conduzam à novas incursões do tema. Apesar de considerar que ao adotar determinado pressuposto analítico, o pesquisador já imprime certo viés às suas interpretações e conclusões, procurou-se no presente estudo verificar como a teoria se aplica à Foz do Iguaçu.

A pesquisa demonstrou que Foz do Iguaçu em sua classificação mais relevante é um centro turístico de distribuição em virtude do seu principal atrativo. Nesse sentido, além das características de oferta, deve-se considerar o fluxo turístico, a fim de não cometer equívocos (Pimentel, 2020). No que se refere à origem de sua demanda, constitui-se como um destino internacional, quanto a sua demanda externa, ao receber turistas de mais de uma centena de países. Sobre a demanda interna, caracteriza-se como um destino nacional, visto que obtém um fluxo de regiões localizadas a mais de 500 km. Quanto ao volume de seu fluxo classifica-se na posição 3, nível 7 com uma presença simultânea média próxima de 17.666 turistas em um mesmo dia.

Como implicações práticas da investigação, dentro do interesse do planejamento turístico, os resultados indicam que além de assumir um papel de centro de distribuição, Foz do Iguaçu tem capacidade de se tornar um centro de estada. Pode-se observar que o Plano Paraná Turístico 2026 Pacto para um Destino Inteligente, Paraná Turismo (2016) aponta que um 
dos objetivos estratégicos em relação a Foz do Iguaçu é sua consolidação como indutor de demanda turística internacional para o Paraná visando um efeito de desconcentração que beneficie outros destinos paranaenses.

Após as análises foi possível observar que tanto nos dados coletados no TripAdvisor, como em estudos de demanda turística, que as origens dos turistas internacionais não estavam dentro do modelo gravitacional que leva em conta a distância geográfica entre origem e destino, ou atendiam a regra de que quanto mais próximo maior demanda (Rabahy, 2003). Nesse caso, indica-se como limitação da pesquisa que os dados colhidos não são corroborados pelos estudos sistemáticos realizados pelo ICMBio.

Em vista disso, há necessidade de mais estudos a fim de entender melhor esta questão. Além disso, considerando que o foco deste trabalho foi exclusivamente o município de Foz do Iguaçu, o destino se insere em um contexto maior, que engloba os países vizinhos. Logo, novas pesquisas poderão levantar dados também do Paraguai e da Argentina para agregar ao que aqui foi exposto.

\section{REFERÊNCIAS}

Agência de Notícias do Paraná. (2020). Parque Nacional do Iguaçu bate recorde de visitantes

2019.http://www.aen.pr.gov.br/modules/noticias/article.php?storyid=105231

\&tit=Parque-Nacional-do-Iguacu-bate-recorde-de-visitantes-em-2019

Almeida, M. (2006). Matriz de avaliação do potencial turístico de localidades receptoras.(Tese de doutorado) Escola de Comunicação e Artes, Universidade de São Paulo, São Paulo, São Paulo, Brasil.

Alvares, D. F., Dalonso, Y. D. S., \& Lourenço, J. M. (2019). Modelos de Avaliação de Destinos Turísticos: concepção e aplicabilidade. Revista Turismo em Análise, 30(1), 1-23. Doi: https://doi.org/10.11606/issn.1984-4867.v30i1 pl-23

Barrado-Timon, D.A. (2004). El concepto de destino turístico. Una aproximación geográfico-territorial. Estúdios Turísticos, 160, 45-68.

Boullón, R. C. (2005). Os municípios Turísticos. Bauru: Edusc. 
Boullón, R. C. (2006). Planificación del espacio turístico (4a. ed.). México: Trillas.

Castro, F. J. G. \& Gândara, J. M.G. (2018). A regionalização do turismo no Estado do Paraná sob a perspectiva do marketing. Marketing \& Tourism Review. 4(1), $1-25$.

Castro, F. J. G. (2020) Fatores explicativos da oferta e da demanda dos destinos turísticos paranaenses. (Dissertação de Mestrado). Universidade Federal do Paraná, Curitiba, Paraná, Brasil.

Corrêa, R. L. (2000). Espaço, Um Conceito Chave da Geografia. In I. E. Castro, P. C.C. Gomes, \&R. L. Corrêa. (Orgs.), Geografia Conceitos e Temas. (2a ed., pp. 15 - 47), Rio de Janeiro: Bertrand Brasil.

Costa, R. M. \& Lucca Filho, V. (2016). Turismo e espaço urbano: notas preliminaries. Revista Eletrônica da Administração e Turismo. 4(4), 42-57.

Cury, M. J. F. (2010). Territorialidades Transfronteiriças do Iguassu (TTI): Interconexões, Interdependências e Interpenetrações nas cidades da tríplice fronteira: Foz do Iguaçu (BR), Ciudad del Este (PY) e Puerto Iguazú (AR). (Tese de Doutorado). Universidade Federal do Paraná, Curitiba, Paraná, Brasil.

Feger, J. E. (2010). Regionalização do turismo na área de influência dos municípios de Marcelino Ramos (RS) e Piratuba (SC). (Tese de Doutorado) Universidade de Santa Cruz do Sul, Santa Cruz do Sul, Rio Grande do Sul, Brasil.

Feger, J. E., Fischer, A., Moraes, P. E. S., \& Siepmann, V.D. (2013). A hierarquia dos municípios turísticos localizados na fronteira gaúcha e catarinense e suas implicações para o planejamento do turismo regional. Seminário Internacional sobre o Desenvolvimento Regional.Santa Cruz do Sul, Rio Grande do Sul, Brasil, 6. Recuperado de https://www.unisc.br/site/sidr/2013/Textos/255.pdf

Fratucci, A.C. (2014). Turismo e território: relações e complexidades. Caderno Virtual de Turismo, 14(1), 87-96.

Granovetter, M.(1973). The StrengthofWeakTies. American JournalofSociology, 78(6), 1360-1380.

Instituto Brasileiro de Geografia e Estatística (IBGE). (2017). Divisão regional do Brasil. Recuperado de https://www.ibge.gov.br/geociencias/organizacaodo-territorio/divisao-regional/15778-divisoes-regionais-dobrasil.htmle edicao $=15905 \& t=a c e s s o-a o-p r o d u t o$

Instituto Brasileiro de Geografia e Estatística (IBGE). (2019). Cidades e Estados. Recuperado de https://www.ibge.gov.br/cidades-e-estados/pr/foz-doiguacu.html 
Instituto Chico Mendes de Conservação da Biodiversidade (ICMBio). (2012). Turistas de 160 países visitaram o Parque Nacional do Iguaçu em 2011. Recuperado de https://www.icmbio.gov.br/portal/ultimas-noticias/20geral/2475-turistas-de-160-paises-visitaram-o-parque-nacional-do-iguacu-em2011

Lacoste, Y. (1988). A geografia - isso serve em primeiro lugar, para fazer a guerra. Campinas: Papirus.

Liu, F., Zhang, J., Chen, D., Liu, Z. \& Lu, S.(2012). Roles andFunctionsofTourism Destinations in Tourism Region of South Anhui: A Tourist Flow Network Perspective. Chinese Geographical Science, 22(6), 755-764.Doi: https://doi.org/10.1007/s1 1769-012-0557-6

Massukado, M. S., \& Teixeira, R. M. (2006). Políticas públicas, recursos turísticos e recursos organizacionais: o caso de Foz do Iguaçu, Paraná. Turismo-Visão e Ação, 8(2), 201-222.

Middleton, V. T. C., \& Clarke, J. (2002). Marketing de turismo: teoria e prática. Rio de Janeiro: Campus.

Ministério do Turismo (MTur). (2018). Dados e Fatos. Recuperado de http://www.dadosefatos.turismo.gov.br/2016-02-04-1 1-54-03/demandatur\%C3\%ADstica-internacional.html

Miskalo-Cruz, M., \& Gândara, J. M. (2016). Indicadores para monitoramento e gestão de destinos turísticos inteligentes. CULTUR, 10(2), 3-22.

Munzert, S.,Rubba, C., Meibner, P.\&Nyhuis, D. (2014). Automated data collectionwith R: A practical guide to web scraping and text mining. United Kingdom: John Wiley\& Sons.

Paraná Turismo. (2016). Plano Paraná Turístico 2026 - Pacto para um destino inteligente, Curitiba (PR). Recuperado de http://www.turismo.pr.gov.br/arquivos/File/institucional/PLANO_DE_TURISMO/ ParanaTuristico2026documentocompleto_1.pdf

Pearce, D. (2003). Geografia do turismo: fluxos e regiões no mercado de viagens. São Paulo: Aleph.

Pimentel, T.D. (2020). A gestão de operações em organizações da cadeia produtiva do turismo: análise da oferta de atrativos culturais em Juiz de For a (MG). Marketing \& Tourism Review, 5(2), 1-42. Doi: 10.29149/mtr.v5i2.5966

Rabahy, W. (2003). Turismo e desenvolvimento: estudos econômicos e estatísticos no planejamento. Barveri: Manole. 
Ramos, R. G. \& Lopes, W.G.R. (2013). Proposta metodológica de avaliação qualitativa de corredores turísticos: considerações sobre o trecho da rodovia BR 343 entre Teresina e o litoral do Piauí, Brasil. Caderno Virtual de Turismo, $13(1), 67-84$.

Ramos, R.G. \& Lopes, W.G.R. (2012). Zonificación turística de la región centronorte del estado de Piauí (Brasil). Aplicación de la teoría del espacio turístico de Roberto Boullón. Estudios y Perspectivas en Turismo, 21 (2), 417-435.

Rodrigues, A. A. B. (2011). Geografia e Turismo - Notas Introdutórias. Revista Do Departamento De Geografia, 6, 71-82. Doi: https://doi.org/10.7154/RDG.1992.0006.0006

Scott, J. (2000).Social Network Analysis: a handbook. (2aed). London: SagePublications.

Scott, N., Baggio, R.\& Cooper, C. (2008). Network AnalysisandTourismFromTheorytoPractice.Toronto: ChannelViewPublications.

Secretaria Municipal de Turismo de Foz do Iguaçu/PR \& Secretaria de Estado do Turismo do Paraná. (SMT/SETU). (2012). Estudo de demanda turística de Foz do Iguaçu 2011 / 2012.2 Recuperado de http://www.turismo.pr.gov.br/arquivos/File/DemandaTuristicaFozdolguacu201 12012.pdf

Secretaria Municipal de Turismo de Foz do Iguaçu/PR. (SMT). (2019a). Tabela de Atrativos Turísticos e Entretenimento. Recuperado de http://www.pmfi.pr.gov.br/ArquivosDB? $i d M i d i a=108601$

Secretaria Municipal de Turismo de Foz do Iguaçu/PR. (SMT). (2019b) Inventário Técnico de Estatísticas Turísticas. Recuperado de http://www.pmfi.pr.gov.br/ArquivosDB? ?idMidia=108547

Silge, J. \& Robinson, D. (2017). Text mining with R: A tidy approach. United States ofAmerica: O' Reilly Media, Inc.

Silva, D. S. \& Gândara, J. M. G. (2016). Reputação online dos spas de Foz do Iguaçu - PR, Brasil. Marketing \& Tourism Review. 1 (2), 1-30.

Soares, J. G., \& Cardozo, P. F. (2012). Metodologia para aferimento de potencialidade turística: um estudo de caso. Revista Espaço Acadêmico, $11(128), 171-179$.

Suzart, V., Ribeiro, R.M., \& Moraes, E.H. (2016). Planejamento do turismo sob a perspectiva da análise espacial: um estudo em Paranapiacaba/SP. Applied Tourism, 1 (2), 135-151. Doi: 10.14210/at.v1n2.p135-151 
Valls, J., Bustamante, J., Gusmán, F., \& Vila, M. (2006). Gestão integral de destinos turísticos sustentáveis. Rio de Janeiro: Editora FGV.

Vieira, I.K.R., Knupp, M.E.C.G., \& Costa, M.R. (2014). Gestão integrada e descentralizada; desenvolvimento social e turístico no Destino Iguassu. Fórum Internacional de Turismo do Iguassu. Foz do Iguaçu, Paraná, brasil, 8. Recuperado de https://festivaldascataratas.com/wpcontent/uploads/2014/01/3.-GEST\%c3\%830-INTEGRADA-E-DESCENTRALIZADADESENVOLVIMENTO-SOCIAL-E-TUR\%c3\%8dSTICO-NO-DESTINO-IGUASSU.pdf

Visitlguassu. (2020). O que fazer a noite.https://www.iguassu.com.br/o-quefazer/o-que-fazer-a-noite/cassinos/

Walter, S. A., Bach, T. M.\& Barbosa, F. (2012). Estrutura das Redes Sociais e Bibliometria: Uma análise longitudinal da Abordagem de Estratégia como Prática. Encontro da ANPAD. Rio de janeiro, Rio de Janeiro, Brasil, 36. Recuperado de: http://www.anpad.org.br/diversos/down_zips/63/2012_ESO2812.pdf

Wu, M. (2012, june, 22). Fromweaktiestostrong ties: community vs. social networks 3. Khoros Atlas. http://lithosphere.lithium.com/t5/s cience-of-social-blog/FromWeak-Ties-to-Strong-Ties-Community-vs-Social-Networks-3/ba-p/6834 